\title{
I WASN'T EXPECTING COMPANY
}

Chagrin to say, I felt before, a sleeve in a sliding door.

"I'll continue to think about it," says one derisive nightcap, nodding off into execution.

By morning, it's no one else's business: Ebenezer in nylons, with her hair back, outlooking a double stroller whistling by.

Last I remember, I was, a bulge in my shorts, 69 adding dignity to my name in a washroom stall.

It's come to this, phantom riding the ceiling fan on a low gear, the desk papers riffling a breeze,

such anterior scene, matchbook strike, snuffed again, her gingham hairs still in harm's way. 